\title{
A Cross-Cultural Validation of Consumer Arrogance Scale in Turkey and Romania
}

\section{Tüketici Kibiri Ölçeğinin Türkiye ve Romanya'da Çapraz Kültürel Geçerliliği}

\author{
Betül BALIKCIOGLU ${ }^{1}$ \\ Muzeyyen ARSLAN²
}

\author{
https://orcid.org/0000-0001-7043-2544 \\ https://orcid.org/0000-0002-9852-7243
}

\begin{abstract}
Consumer arrogance (CA) is a new notion in consumer behavior, which is still unclear if CA has the same meaning in cross-cultures. The purpose of this study is to test the cross-cultural validation of the CA scale in Turkey and Romania, which are considered as collectivist cultures and developing countries. An empirical study was conducted on 145 Turkish and 147 Romanian university students. The crosscultural validation tested via configural, metric, and covariance methods. A confirmatory factor analysis was used to test the validity of the measurement theory. The current research demonstrates the CA scale has an adequate fit to the data in each sample and across-cultural invariance between two countries. Also, the results indicate that the CA scale can be established as a second order construct and it is predicted by materialism.
\end{abstract}

Keywords: Arrogance, Consumer arrogance, Crosscultural validity, Materialism.

\section{Introduction}

Most of attention in studying consumer behavior aspects is the consumption behaviors which serve to satisfy consumer's identity motives. For instance, consumers who need distinctiveness and self-esteem motives can satisfy these feelings by purchasing a rare, status-linked products (Shrum et al., 2013). In doing so, they make connections between positive self-identity motives and the symbolic meanings they attribute to the products (Ger \& Belk, 1996). Due to view material possessions as an extension of themsel-

\section{ÖZET}

Tüketici kibiri, tüketici davranışı alan yazınında yeni bir kavramdır. Bununla birlikte, tüketici kibirinin çapraz kültürlerde aynı anlama sahip olup olmadığı hala belirsizdir. Bu yazının amacı tüketici kibiri ölçeğinin, toplulukçu kültüre sahip olan ve gelişmekte olan ülkeler olarak kabul edilen Türkiye ve Romanya'da kültürler arası güvenilirliğini ve geçerliliğini test etmektir. Bunun için, 145 Türk ve 147 Romen üniversite öğrencisi üzerinde görgül bir çalışma yürütülmüştür. Ölçeğin kültürler arası geçerliliği, yapısal değişmezlik, metrik ve kovaryans yöntemleriyle test edilmiştir. Ölçüm teorisinin geçerliliğini test etmek için doğrulayıcı faktör analizi kullanılmıştır. Araştırma sonuçları, CA ölçeğinin her bir örneklemdeki verilerle istatistiksel olarak kabul edilebilir uyumu ve iki ülke arasındaki kültürel değişmezliği gösterdiğini ortaya çıkarmıştır. Ayrıca bulgular, CA ölçeğinin ikinci dereceden bir yapı olarak kurulabildiğini ve materyalizm tarafından tahmin edildiğini göstermektedir.

Anahtar Kelimler: Kibir, Tüketici kibiri, Çaprazkültürel geçerlilik, Materyalizm. 
narcissistic personalities, which are generally acted with arrogance (Kasser, 2002). The underlying motives of goals that mentioned above are actually satisfying the needs of individuals (Vignoles, Golledge, Regalia, Manzi \& Scabini, 2006).

Some researchers (Silverman, Johnson, McConnell \& Carr, 2012) investigated arrogance as a trait and examined the situations in which people are perceived as arrogant. Also, people are perceived as arrogant when they communicate their quality and accentuate that it comes from their superiority and global self (Johnson et al., 2010). When considering arrogance as a personality trait which reflects the tendency to communicate one's qualities and self-worth to others (Lewis, 2000, 2016), it was extended to the marketing literature by addressing consumer arrogance notion. CA is conceptualized and defined by Ruvio \& Shoham (2016) as people's proclivity for demonstrating their social superiority through the acquisition, utilization, or display of consumer goods (p. 3898). In this contribution, these two scholars developed a CA scale as a multi-dimensional trait. This new notion rooted from the symbolic meaning of consumption that suggesting consumers use products as symbols to create self-identity, to maintain their self-concept, to express their self, to convey personal and social achievements and to reflect their social status to others (Holman, 1981; Solomon, 1983; Belk, 1988; Hirschman \& LaBarbera, 1990).

It seems that the scarcity of studies on arrogance stems from the lack of the measurement instrument of arrogance in marketing literature (Ruvio \& Shoham; 2016). To fill this gap, Ruvio \& Shoham (2016) developed a CA scale to measure it in the marketing context. Researchers have investigated CA in the USA and Israel which are western cultures also modern and developed countries. However, it is still uncertain that consumer arrogance has the same meaning across different cultures. The validity and reliability of the scale in non-Western societies are uncertain as well. There is a need to test the cross-cultural validity of CA construct in different cultures.

This study is designed to test reliability and validity of CA scale that have not been tested yet in Turkey and Romania, which are considered developing non-Western countries as well as collectivist. With this study, it is expected that the CA cross-culturally equivalent and valid scale. As mentioned above, CA is a new notion, investigating it in different cultures will facilitate to improve the comprehension of CA in cross cultural setting. In this manner, this study aims to establish measurement equivalence across cultures and to enrich the consumer behavior understanding by using materialism in predicting CA.

\section{Literature Review}

Arrogance is defined as a chronic belief of superiority and exaggerated self-importance that is demonstrated through excessive and presumptuous claims (Brown, 2012, p. 555) and used as to refer one of the seven deadly vices, which are strongly correlated with dark traits: machiavalism, psychopaty, narcissism (Veselka, Giammarco, Vernon, 2014). Paulhus \& Williams (2002) considered dark trait an aspect of personality traits that are socially undesirable and resembles the seven deadly sins. Although the dark traits are undesirable traits in the interpersonal context, they are favorable on the personal point of view since they serve a purpose on the behalf of person instead of group (Kurt \& Paulhus, 2008). Arrogance is grounded on interpersonal dynamics and sense of superiority by manifestation of overt and excessive behaviors over others (Johnson et al., 2010).

The early studies regarded arrogance as a psychoanalytic term which is a component of narcissism (Emmons, 1984). Although narcissism with the belief of superiority, shares the same meaning with arrogance they are different from each other. While arrogance emerges as open behaviors during interpersonal interactions, narcissism involves both open and confidential behavior (Johnson et al., 2010).

Although, arrogance is characterized by the words of 'hubris, contemptuous, vanity, and conceited', it differs from them. The conceptual origins rely on pride, which is a two-faced construct: authentic and hubristic. However, arrogance differs from pride at the attribution of success point. Pride arises from the attribution of a specific achievement to the efforts, prosocial behaviors whereas arrogance stems from the attribution of achievements to one's global self and abilities (Verbeke, Belschak \& Bagozzi, 2004; Tracy \& Robins, 2007).

Arrogance is embedded to social context and refers to exaggerate one's own superiority while underestimating others (Johnson et al., 2010). People feel better when they perceive themselves superior against to others (Locke \& Nekich, 2000). Symbolically, possessions can be used as clues to show that people are superior to others (Hirschman \& LaBarbera, 1990). Thus, Ruvio \& Shoham (2016) suggested that arrogant consumers project their arrogant inclinations via 
consumption. They constructed CA as a multi-dimensional trait and developed the original 21-items CA scale (see appendix A) consisting of four factors which are consumer superiority, consumer bragging, exhibitionism-based consumption, and image-based consumption. Consumer superiority refers to the individuals' sense of superiority. Individuals high on CA link their purchasing behaviors to their superior self. Arrogant consumers associate the superior quality of the products they bought with their global self, and they directly derive their superior qualities from the quality of products they purchased (Hayward \& Hambrick, 1997; Verbeke et al., 2004). Furthermore, those who scored high on CA regard their purchasing behaviours as an achivement and tend to share these achievements with others vaingloriously (Verbeke et al., 2004). Any such intended behaviours are explained as consumer bragging dimension of $\mathrm{CA}$.

Exhibitionism-based consumption refers to the social nature of CA. Arogance manifests in social interactions (Johnson et al.,2010) and arrogant people need social approval from others to enhance their self- views with feedbacks from those surrounding others (Aghababaei \& Błachni, 2015; Egan, Chan, \& Shorter, 2014; Johnson et al.,2010). Exhibisionistic and conspcious purchases signals their exceptional appearance to others and helps to inflate their ego (Ruvio \& Shoham, 2016).

The desire to project arrogant consumers' belief of superiority over others leads them to purchase status products and brands that signal uniqueness, conspicious values (Lee, Ko \& Megehee, 2015), which is called image-based consumption dimension of CA. Image-based and exhibitionism-based purchases are the way of representing ideal self-image, status and superior self to others.

In their study, Ruvio \& Shoham (2016), used materialism as a predictor of CA and they found a positive relationship between the two. In the marketing literature one of the most common construct linking identity motives to consumption behaviors is materialism. Materialism is a construct emphasized the importance the individuals attached on possessions. On consumer perspective materialism, a construct that potently recognized with consumption, is explained as the importance that attached to the possessions. Individuals who are high on the materialism scores put these possessions on a central place in their life with the belief of providing the greatest source of happiness (Belk 1985; Richins \& Dawson 1992). Also, ma- terialism has been considered a kind of self-centered traits such as selfishness (Bauer et al. 2012). The most widely used materialism scale in consumer behavior literature is the Richins \& Dawson's (1992) 18-items materialistic value scale that we used in this study (see appendix B), which involves three dimensions: (1) use of material possessions to make judgement about success of others and oneself, (2) acquisition centrality that is importance of possessions in one's life; and (3) acquisition of possession as the pursuits of happiness. Individuals scored high on materialism regard amount of possessions as an indicator of how success anyone in life, put material possessions in a prominent place in their life and believe material possessions lead them to happiness (Richins \& Dawson, 1992).

The early studies regarded materialism as a western trait that is seen in developed and affluent countries since the marketing strategies are driving hedonism effectively in that countries. However with the effect of globalisation and Westernisation the consumers in developing countries or third world countries became consumer oriented (Campbell, 1987; Ger \& Belk 1996). The level of materialism may vary according to the level of development of countries. For example, materialism was found higher in Turkey and Romania than in the USA and Europe (Ger \& Belk, 1996).

On the dark side aspect of materialism the relationship between materialism and environmental and social concerns are examined. Materialistic values effect people negatively and leads them insensitivity to environmental and community issues (Clump, Brandel \& Sharpe, 2002; Kilbourne \& Pickett, 2008). Materialistic individuals generally consume huge amount of natural sources than necessary (Winter, 2004). Because people detest to think of themselves as selfish and environmentally insensitive. There may occur an incongruence between material self and ideal self that drives the feeling unhappiness and dissatisfaction (Kilbourne \& Pickett, 2008). CA focuses on how consumption-related activities convey the superiority of individuals. Consumers with high levels of arrogance have a belief that they are superior to others in terms of the acquisition and use of possessions and they are linking the superior qualities of the products they purchase with their superior quality of their-selves which is related to materialism (Ruvivo \& Shoham, 2016). Materialism and CA are related constructs as they reflect tendencies of individuals via consumption; therefore materialism was investigated as a predictor of CA in the current study. 


\section{Methodology}

\section{Sample}

The data were gathered from two countries, Turkey and Romania. These two countries exhibit cultural similarities based on Hofstede's (1990) individualism and collectivism dimensions. The CA scale is developed and validated in Israel and the US. Although the American society has been considered as individualistic with a score of 91, in Hofstede's (2001) study, the Israeli society is considered as a blend of individualistic and collectivistic cultures with a score 54. Individualism emphasizes on the uniqueness of the person, self-reliance and competitiveness. On the other hand collectivism focuses on interpersonal connection and harmony, not bragging (Markus \& Kitayama, 1991). According to Alicke \& Sedikides (2009), people are self-promoting in individualistic cultures and when self-promotion suggests arrogance, it damages interpersonal relationships. In contrast, people are more modest in collectivist cultures and modesty avoids the risks of arrogance. Maheswaran \& Shavitt (2000) provide useful literature that shows how culture, individualist versus collectivist, differentiated consumer behavior. Therefore, current study evaluate the construct validity of the CA within and across a collectivist cultural context in Turkey and Romania. These two countries were chosen because they are both less developed non-Western countries and collectivist with 37 (Turkey) and 30 (Romania) individualistic scores based on Hofstede's (1990) cultural dimensions. Thus, it is important to investigate the CA scale in a non-Western collectivist context.

An efficient way to make the samples comparable in two countries university students sample will be relatively homogeneous for this study. Therefore, we intend to reduce the random error that might occur by using heterogeneous sample (Calder, Lynn \& Alice, 1981). The survey applied in the same way via self-report questionnaire administrated to convenience samples of university students in class in both country as voluntarily and without extra credit. The sample included a total of 368 young adults (192 Turkish and 176 Romanian). After deleting the outliers to reach the normally distributed data, the final sample revealed as 292 young adults (145 Turkish and 147 Romanian). Participants age range goes from 18-26 years old, and their average age is $20.76(S d=1.445)$. The majority of the participants were female (71\%).

\section{Measures}

The questionnaire is consisted 39 items for scales and two questions for demographic information. CA was measured by using Ruvio \& Shoham's (2016) scale, which is included 21 items across four dimensions. Materialism was measured by Richins \& Dawson's (1992) scale, which is consisted of three dimensions a total of 18 items. The materialism scale has been tested on the Turkish sample and the Cronbach's alpha coefficient for whole scale is 80 (Karabati \& Cemalcilar, 2010). Also, this scale has been tested on Romanian sample (Zait \& Mihalache, 2014) and alpha coefficient was found 0.84. The Likert-type scale with a five point format was used for all items.

The five-step back-translation method of Brislin, Lonner \& Thorndike (1973, p. 182) was used for translating the original English questionnaire to Turkish. For the Romanian sample, the English version of the questionnaire was administrated because the students were fluent in English. Because as indicated by Albaum, Erickson \& Strandskov (1989) using the scale with its original language in cross-cultural research provides the same results as a translated one.

\section{Data analysis procedure}

To assess the construct validity and cross-cultural equivalence of the Ruvio \& Shoham's (2016) four-factor CA (21 items) scale, the procedures that suggested by Hair, Black, Babin, Anderson \& Tatham (2006, pp. $820-833$ ) is followed. The analysis procedure began with performing the normality test in AMOS because of the confirmatory factor analysis (CFA) used with the maximum likelihood estimation. The univariate normality was assessed by using the proposed threshold of (Finch, West, \& MacKinnon, 1997) for skewness < 2.0 and for kurtosis $< \pm 7.0$ which reveals no significant problems in the data. Multivariate normality is determined by Mardia's multivariate kurtosis (Mardia, 1970).

Then, the internal consistency reliability of the original 21-items CA was assessed for an individual sample by using Cronbach's alpha coefficient (Nunnally, 1979). Because of the data was self-reported, we checked a common method variance (CMV) via Harmon's one factor test (Podsakoff \& Organ, 1986) as loading all of the observable items on a single factor by using CFA.

The construct validity of CA assessed with convergent, discriminant, and nomological validity (Garver \& Mentzer, 1999) for each samples separately as used by Ruvio \& Shoham (2016). While convergent validity 
confirms the relationship between the items and the factor that they belong, discriminant validity examines how the items different from other constructs. Following the procedures of convergent validity proposed by Fornell \& Larcker (1981) were used in this study. These are the average variance extracted (AVE) and the composite reliability (CR) of each construct. Based on Hair et al. (2006) recommendation all CR values for the dimensions are expected to be a value of 0.70 and higher. Also, when AVE values equals or exceeds 0.50, convergent validity is assessed to be adequate. However, for discriminant validity, all AVE's should be higher than maximum squared variance (MSV) involving the constructs (Fornell \& Larcker, 1981). MSV is the square of the highest correlation between the constructs. Nomological validity means that two or more theoretical and / or empirical concepts should also be correlated (Cronbach \& Meehl, 1955).

In evaluating the model fit, we used five types of indicators, which are the Chi-Square (CMIN), the Root Mean Square Error of Approximation (RMSEA), the Normed Fit Index (NFI), the Tucker-Lewis Index (TLI), and the Comparative Fit Index (CFI). The CMIN value is the most basic measurement used to test the overall suitability of the model. An appropriate model is expected to give meaningless results at $p<0.005$ (Barrett, 2007). RMSEA is a statistic that gives information about the compatibility of the hypothesized model parameters with the covariance matrix of the population (Byrne, 2011: 664). RMSEA can be within the range of 0.03 to 0.08 in the $95 \%$ confidence interval (Rigdon, 1996: 369-379). The NFI statistic compares the $x 2$ value of the model with the $X 2$ value of the zero model. The $\mathrm{NFI}$ value can be between 0 and 1 , and a threshold value of 0.90 is considered to represent good fit (Hu \& Bentler, 1999). TLI statistic were developed to eliminate the effect of sample size. In addition, the threshold value of TLI can be greater than 0.80 and high threshold values such as TLI> 0.95 are also found in the literature (Hu \& Bentler, 1999; Byrne, 2011: 684). CFI also takes into account sample size and gives good results even in small samples and the threshold is generally considered greater than 0.90 (Byrne, 2011).

Since the purpose of this study is to test the cross-cultural invariance of the CA scale, the multi-group analysis of invariance used by assessing configural, metric, and factor covariance invariance as proposed by Hair et al. (2006). Configural invariance means that the construct is conceptualized with the same way across-samples without constraints imposed across samples. Metric invariance confirms that all factor loadings are equal across-samples by constraining the factor loadings across-groups. Factor covariance invariance indicates that the factor loadings and intercepts were equally constrained in both samples.

\section{Findings}

The results of the univariate normality test showed that the value of skewness ranged from -.337 to +1.138 and the value of kurtosis ranged from -.989 to +1.232 for the Turkish sample. For the Romanian sample, the value of skewness ranged from -.394 to +1.017 and the value of kurtosis ranged from -.925 to +.462 . Although, these values are within the ranges of normal distribution the multivariate kurtosis values revealed as 80.181 (c.r. = 17.873) for the Turkish sample and 53.593 (c.r. = 11.438) for the Romanian sample. According to Mardia (1974) since the c.r. is $<5$, the data suggests multivariate normality distributed (Byrne, 2013). For lowering the multivariate kurtosis in this study, we deleted the outliers by using the measure of their Mahalanobis distances until the multivariate kurtosis index reaches the desired level. The second multivariate kurtosis resulted in a value of 14.916 , with the 2.889 critical ratio (c.r.) for the Turkish sample and in a value of 11.364, with the 2.217 c.r. for the Romanian sample. Thus, the data supports multivariate normally distribution since the c.r. values < 5 (Byrne, 2013) for both samples. After deleting the outliers, which are fourty seven from Turkish sample and twenty nine from Romanian sample, the final sample included a total of 292 observations (145 Turkish and 147 Romanian) which is considered adequate sample size for SEM (at least one hundred observations) suggested by Hair et al. (2006).

After normality test, we first assessed the reliability of the overall CA for both samples, which are resulted in a good Cronbach's alpha coefficients ( $a=0.92$ for the Turkish sample and $a=0.93$ for the Romanian sample. Then, the reliability based on four-dimensions of CA scale is addressed for the two samples. In the Turkish sample, the coefficients ranged from 0.84 (consumer superiority dimension) to 0.89 (image-based consumption dimension) and from 0.82 (consumer bragging dimension) to 0.89 (image-based consumption dimension) for the Romanian sample. Thus, overall CA and all of its dimensions have reliable Cronbach's alpha coefficients, which is considered to be good as suggested by Nunnally (1979). 
Because the data were self-reported, we assessed a common method variance (CMV) via Harmon's one factor test (Podsakoff \& Organ, 1986) as loading all of the observable items on a single factor using CFA. The results of Harmon's one factor test revealed a poor fit for both of countries (Turkey $\mathrm{X} 2=998.848, \mathrm{~d} f=189, \mathrm{p}$ $\leq .000 ; \mathrm{CFI}=0.56 ; \mathrm{NFI}=0.51 ; \mathrm{TLI}=0.51, \mathrm{RMSEA}=0.17$ / Romania $\mathrm{X} 2=755.749, \mathrm{~d} f=189, \mathrm{p} \leq .000 ; \mathrm{CFI}=0.66$; $\mathrm{NFI}=0.60, \mathrm{TLI}=0.66$, RMSEA $=0.14$ ). Thus, it can be inferred that there is no risk of CMV bias.
The CFA was carried out to determine the factor-structure of CA scale with 21 items for the Turkish sample and for the Romanian sample separately. The CFA results in both samples produced poor fit indexes. To improve fit indexes of both samples we followed the common practice by deleting five items that factor loadings lower than 0.50 (Hair et al., 2006, 133). Thus, the original scale reduced to 16 items for to maintain its validity. Table 1 , reports the results of the CFA for the two samples.

Table 1: Factor Loadings and Correlations between Dimensions of CA - CFA Analysis

\begin{tabular}{|c|c|c|c|}
\hline \multicolumn{2}{|l|}{ Factor loadings } & \multirow[t]{2}{*}{ Turkey } & \multirow[t]{2}{*}{ Romania } \\
\hline Image-based consumption & & & \\
\hline & $\mathrm{IBC} 1$ & 0.92 & 0.84 \\
\hline & $\mathrm{IBC} 2$ & 0.92 & 0.93 \\
\hline & $\mathrm{IBC} 3$ & 0.88 & 0.85 \\
\hline & $\mathrm{IBC} 4$ & 0.80 & 0.63 \\
\hline AVE & & $78 \%$ & $67 \%$ \\
\hline CR & & 0.93 & 0.89 \\
\hline \multicolumn{4}{|c|}{ Exhibitionism-based purchasing (EPB) } \\
\hline & EPB3 & 0.81 & 0.80 \\
\hline & EPB4 & 0.89 & 0.81 \\
\hline & EPB5 & 0.72 & 0.74 \\
\hline & EPB6 & 0.60 & 0.85 \\
\hline AVE & & $58 \%$ & $57 \%$ \\
\hline CR & & 0.84 & 0.84 \\
\hline \multicolumn{4}{|l|}{ Consumer bragging (CB) } \\
\hline & CB1 & 0.74 & 0.68 \\
\hline & $\mathrm{CB} 2$ & 0.94 & 0.96 \\
\hline & CB3 & 0.63 & 0.70 \\
\hline & CB4 & 0.54 & 0.57 \\
\hline AVE & & $56 \%$ & $54 \%$ \\
\hline$C R$ & & 0.83 & 0.82 \\
\hline \multicolumn{4}{|l|}{ Consumer superiority (CS) } \\
\hline & CS1 & 0.68 & 0.69 \\
\hline & $\mathrm{CS} 2$ & 0.86 & 0.87 \\
\hline & CS3 & 0.83 & 0.83 \\
\hline & CS4 & 0.66 & 0.74 \\
\hline AVE & & $58 \%$ & $61 \%$ \\
\hline CR & & 0.84 & 0.86 \\
\hline \multicolumn{4}{|l|}{ Correlations (variances) } \\
\hline $\mathrm{IBC}$ & EPB & $0.44(0.19)$ & $0.57(0.32)$ \\
\hline IBC & $\mathrm{CB}$ & $0.38(0.14)$ & $0.51(0.26)$ \\
\hline $\mathrm{IBC}$ & CS & $0.48(0.23)$ & $0.51(0.26)$ \\
\hline EPB & $\mathrm{CB}$ & $0.56(0.31)$ & $0.72(0.51)$ \\
\hline EPB & CS & $0.50(0.25)$ & $0.57(0.32)$ \\
\hline $\mathrm{CB}$ & CS & $0.54(0.29)$ & $0.48(0.23)$ \\
\hline
\end{tabular}

All loadings and correlations are significant at $\mathrm{p}<.001$ level. 
The modified measurement model of CA scale has a correlated four-factor structure with four items loading on the image-based consumption factor (IBC), four items loading on the consumer bragging factor (CB), four items loading on the exhibitionism-based purchasing $(E B C)$, and four items loading on the consumer superiority factor (CS) (see Appendix A for retained and deleted items).

Although the re-specified four factor model has a significant chi-square (Turkey: $\mathrm{X} 2(\mathrm{CMIN})=202.589$, $\mathrm{d} f=97, \mathrm{p} \leq .000, \mathrm{x}^{2}(\mathrm{CMIN}) / d f=2.089$ / Romania: $\mathrm{X} 2(\mathrm{C}-$ $\left.\mathrm{MIN})=181.098, \mathrm{~d} f=97, \mathrm{p} \leq .000, \mathrm{X}^{2}(\mathrm{CMIN}) / d f=1.867\right)$ other fit indices demonstrate acceptable statistics based on Byrne (2011) recommendations (Turkey: CFI $=0.93 ; \mathrm{NFI}=0.89 ; \mathrm{TLI}=0.91, \mathrm{RMSEA}=0.08 /$ Romania: $\mathrm{CFI}=0.94 ; \mathrm{NFI}=0.89, \mathrm{TLI}=0.93, \mathrm{RMSEA}=0.07$ ).

All factor loadings are greater than 0.50, with dimensions' AVE values ranging from $54 \%$ to $78 \%$, and CR values for the four factors above 0.80 are providing scale convergent validity. Additionally, discriminant validity was established based on Fornell \& Larcker's (1981) procedure. All of the AVEs are greater than the shared variance between each pair of factors in both of the countries. Thus, this test doesn't suggest prob- lems with discriminant validity. In addition, fit statistics of the measurement model of four-factor structure CA for both countries is good (Table 2). We then further examined whether the results from the sample of Turkish students can be cross-validated using the sample of Romania students. Table 2 summarizes the results of the measurement equivalence a cross-samples. Each progressive test supports the cross-validation.

The configural invariance test the same baseline measurement model on both countries simultaneously. The results demonstrated good fit statistics $(\mathrm{X} 2=$ 383.690, $\mathrm{d} f=194 ; \mathrm{NFI}=0.89 ; \mathrm{TLI}=.92 ; \mathrm{CFI}=0.94 ; \mathrm{RM}-$ SEA $=0.05)$ and supports the four factor measurement model in both countries. Constraining the loading estimates has not worsened fit of the unconstrained model and the change in chi-square in not significant $(\Delta \times 2(12)=10.72 ; p=.553)$. A non-significant Chi-square supports that the factor loadings are equal across countries. Similarly, the test of covariance invariance provides a good fit $(\mathrm{X} 2=402.910, \mathrm{~d} f=213$; NFI $=0.89$; $\mathrm{TLI}=.93 ; \mathrm{CFI}=0.93 ; \mathrm{RMSEA}=0.05$ ). Thus, statistically the model is not different from the baseline model $(\Delta \times 2(17)=8.5 ; p=.291)$, and it means that the factor correlations are equal across countries.

Table 2: Cross-Cultural Validation Statistics for the CA Scale

\begin{tabular}{|c|c|c|c|c|c|c|c|c|c|c|}
\hline Model & 守 $\frac{\frac{0}{\sigma}}{\frac{0}{\sigma}}$ & $\hbar$ & 2 & $\sum_{\infty}^{\mathbb{4}}$ & $\bar{u}$ & 肯 & $\vec{F}$ & $\underset{8}{x}$ & $\frac{4}{8}$ & 2 \\
\hline \multicolumn{11}{|l|}{ Individual Groups: } \\
\hline Turkey & 202.59 & 97 & .000 & 0.08 & 0.93 & 0.89 & 0.91 & & & \\
\hline Romania & 181.10 & 97 & .000 & 0.07 & 0.94 & 0.89 & 0.93 & & & \\
\hline \multicolumn{11}{|l|}{ TF-Factor Structure } \\
\hline Equivalence & 383.69 & 194 & .000 & 0.05 & 0.94 & 0.89 & 0.92 & & & \\
\hline \multicolumn{11}{|l|}{ Factor Loading } \\
\hline Equivalence & 394.41 & 206 & .000 & 0.05 & 0.93 & 0.89 & 0.92 & 10.72 & 12 & 0.553 \\
\hline \multicolumn{11}{|l|}{ Factor Covariance } \\
\hline Equivalence & 402.91 & 213 & .000 & 0.05 & 0.93 & 0.89 & 0.93 & 8.5 & 7 & 0.291 \\
\hline
\end{tabular}

To assess the nomological validity, materialism was used as an antecedent of CA, which is supported by Ruvio \& Shoham's (2016) study that found a positive relationship. Before the nomological validity, we carried out CFA to confirm the three-factor structure of materialism for both countries. The CFA results in both samples indicate poor fit for the three dimensional materialism (Turkey: $X^{2}(C M I N)=327.019, d f=132, X^{2}(C$ $\mathrm{MIN}) / d f=2.477 ; p=.000 ; \mathrm{CFI}=.826 ; \mathrm{NFI}=.743 ; \mathrm{TLI}=.798$; RMSEA=.101 / Romania: $X^{2}(C M I N)=262.397, d f=132$,
$X^{2}(\mathrm{CMIN}) / d f=1.988 ; p=.000 ; \mathrm{CFI}=.886 ; \mathrm{NFI}=.797 ; \mathrm{TLI}=$ .868 ; RMSEA $=.085$ ). To improve the fits of the model we removed two indicators from success factor, four indicators from centrality, and one indicator from happiness that factor loadings lower than 0.50 as suggested by Hair et al. $(2006,133)$ (see Appendix B for retained and deleted items). The modified measurement model of materialism demonstrates acceptable fit statistics (Turkey: $X^{2}(C M I N)=111.527, d f=41, X^{2}(C$ $\mathrm{MIN}) / d f=2.720 ; p=.000 ; \mathrm{CFI}=.90 ; \mathrm{NFI}=.886 ; \mathrm{TLI}=.904 ;$ 
RMSEA $=.080$ / Romania: $X^{2}(C M I N)=82.089, d f=41$, $\mathrm{X}^{2}(\mathrm{CMIN}) / d f=2.002 ; p=.000 ; \mathrm{CFI}=.942 ; \mathrm{NFI}=.893 ; \mathrm{TLI}=$ .923; RMSEA=.083). Next, CR and AVEs were computed for each dimension. The $C R$ values of success were 0.82 and 0.84 , for the Turkish and Romanian samples, respectively. The $C R$ values of the happiness dimension were 0.84 for both of samples. However, the $C R$ values of centrality factor with 0.70 and 0.65 values for the Turkish and Romanian samples, respectively, were failed to fit the recommended level of 0.80 . In addition, the AVEs reached the required 0.50 values for success and happiness dimensions in both samples, except for the centrality dimension with 0.44 in the Turkish sample and 0.41 in the Romanian sample. Therefore, we omitted the centrality factor from the nomological validity analysis.

Before to test the nomological validity, CA subjected to a second order CFA to estimate of the primary construct on its sub-dimensions. The second order fit statistics of CA are good for both countries (unconstrained model: $\chi 2=418.565 ; \mathrm{d} f=200, \mathrm{p}=0.001 ; \mathrm{NFI}=.865$, $\mathrm{TLI}=0.908 ; \mathrm{CFI}=0.924, \mathrm{RMSEA}=0.06 /$ the constrained model: $\mathrm{X} 2=433.378 ; \mathrm{d} f=215, \mathrm{p}=0.001 ; \mathrm{NFI}=0.865$; $\mathrm{TLI}=0.915 ; \mathrm{CFI}=0.924 ; \mathrm{RMSEA}=0.05)$ and the chi-square difference between models is not significant $(\Delta \mathrm{X} 2$ $(15)=14.813 ; p=.465)$.

Then, we assessed the multi-group nomological validity with SEM (structural equation model) to understand the relationships between CA and materialism dimensions which are success and happiness. The results showed a good fit with the data (the baseline model: $\mathrm{X} 2=806.819 ; \mathrm{d} f=536, \mathrm{p}=0.000 ; \mathrm{NFI}=.830, \mathrm{TLI}=$ $0.926 ; \mathrm{CFI}=0.934 ; \mathrm{RMSEA}=0.042)$. Then, the structural weights were constrained to be equal across the two samples. The constrained model was still acceptable and statistically not significant $(X 2=827.142 ; \mathrm{d} f=560$, $\mathrm{p}=0.000 ; \mathrm{NFI}=0.824 ; \mathrm{TLI}=0.930 ; \mathrm{CFI}=0.935 ; \mathrm{RMSEA}$ $=0.041)$. By this constraint a change in Chi-square is non-significant, then the added constraints has not worsened the fit $(\Delta \mathrm{X} 2(24)=20.323 ; \mathrm{p}=0.678)$. Therefore, the nomological validity of CA supported in both countries. The results of the SEM analysis partially confirmed the expected relationships. As expected, the results indicated that the coefficient of path from success dimension of materialism to CA for Turkey ( $\beta$ $=0.55, p<0.001)$ and for Romania $(\beta=0.85, p<0.001)$ were found statistically significant and positive. In addition, while the coefficient of path from happiness dimension of materialism to CA was found statistically significant and positive for Turkey $(\beta=0.36, p<0.001)$, no significant relationships were found for Romania ( $\beta$ $=0.12, p=0.226$ ).

\section{DISCUSSION}

This study investigates the configural, metric, and factor covariance invariance of the 21 -items CA across two countries with a collectivist cultural context, Turkey and Romania, using multi-group analysis. In line with that purpose, the CFA analysis in each sample resulted with 16 items after deleting five items that factor loadings lower than 0.50 (see Appendix A). These items are IBC5 (The image of a product affects my purchase of it), IBC6 (I often buy products that emphasize my social status), EBP1 (I tend to buy products that attract attention), EBP2 (I tend to buy products that make me look meticulous), and CB5 (I tend to choose showy products). The reduced 16-item four-factor CA revealed evidence for full invariance across samples. Because, the three invariance tests indicate that the factor loading pattern, factor structure, and factor covariance revealed to be equivalent across the cultures. Thus, these findings suggest that the 16-item CA may use to make comparisons between samples from similar cultures. In addition, the results showed that CA might be used as a second order construct. While this result supports the findings of Ruvio \& Shoham's (2016), it doesn't support Ruvio \& Shoham's (2007) suggestion that CA is less desirable in a collectivist culture. This finding can be explained by Newman \& Newman's (2014) argument that the globalization has moved cultures to individual values from collective values. Although Ruvio and Shoham (2016) confirmed the CA scale in Israel and the US, our study also contributes to the etic approach (Triandis \& Marin, 1983) by supporting the cross-cultural measurement invariance of the CA in two countries with a collectivist cultural context.

The nomological validity findings show that materialism partially predicts $C A$. Our results show that the success dimension of materialism predicts $C A$ in both samples and happiness dimension only predicts CA in the Turkish samples. Furthermore, the centrality dimension of materialism dropped from the analysis because of its low reliability. In this manner, our research make a significant contributions by displaying that materialism tendencies may understandable with the same way in collectivistic cultural context. This interesting findings may be interpreted in line of the problematic psychometric properties of Richnis \& Dawson's (1992) materialism scale that found in some 
studies (Griffin, Babin, \& Christensen, 2004; Wong, Rindfleisch, \& Burroughs, 2003; Watchravesringkan, 2012). As indicated by Webster \& Beatty (1997) and supported by Watchravesringkan (2012), the mixed-worded scales particularly the reverse-worded items reduced the scale dimensionality in different cultural contexts. In his study Watchravesringkan (2012) found that the Cronbach's coefficient as well as the $C R$ values of the centrality dimension of materialism below the acceptable ranges as recommended by Nunally (1979). Finally, Watchravesringkan (2012) showed that the reduced 10-items materialism scale, without reverse worded items (eight items), invariant across the US and the Thai samples. In addition, although our nomological findings do not fully supported that sub-dimensions of materialism as predictors of $C A$, it should be noted that Ruvio \& Shoham (2016) had been used overall materialism score in their study. When materialism considered as one the important aspects of consumer behavior that influenced by culture (Ger \& Belk, 1996), also it should be considered that the differences will be occured related to its dimensions. Thus, future research needs to replicate Richins \& Dawson's materialism scale with other short versions in non-students samples.

In particular, future research ought to investigate the influence of culture at the individual level by classifying the respondents as independence and interdependence based on Singelis' (1994) self-concept scale. Nevertheless, while arrogance is conceptually distinct from self-esteem (Rosenberg, 1979), it is related with it. High self-esteem is associated with negative qualities such as arrogance and conceit (Gecas, 2009). Heatherton \& Vohs (2000) found that when people with extremely high self-esteem they responded by acting more arrogantly than people with lower self-esteem. On the contrary with that Johnson et al. (2010) showed that arrogant behaviors may lead to low self-esteem. Although there is some inconsistency in results between self-esteem and arrogance in the literature, future research may also explore the relationship between self-esteem and CA.

Due to time and cost constraints the most important limitation of this study is that the CA scale is not translated into Romanian. The future research should established transnational equivalence through traditional translation-back translation procedures. Also, in this research student samples used, which is increased internal validity. However future research would use samples from non-student populations.

\section{Acknowledgements}

The authors would like to thank to Dr. Ayalla A. Ruvio and Dr. Aviv Shoham for their permission to use consumer arrogance scale, and to Prof. Dr. Mihaela Violeta GHICA for helping to collect the data in Romania for this study. Also, the authors warrant that this research has not received any grants from any funding agency. 


\section{REFERENCES}

Ahuvia, A.C. \&Wong, N.Y. (2002). Personality and values based materialism: their relationship and origins. Journal of Consumer Psychology, 12(4), 389-402.

Aghababaei, N., \& Błachnio, A. (2015). Well-being and the Dark Triad. Personality and individual differences, 86, 365-368.

Albaum, G., Erickson, R. \& Strandskov, J. (1989). Questionnaire design in international and cross-cultural research: Is translation necessary? In Gardner M.P. (ed.), proceedings of the society for consumer psychology, American Psychological Association, Washington DC,10-15.

Alicke, M \& Sedikides, C, (2009). Self-enhancement and self-protection: What they are and what they do. European Review of Social Psychology, 20, 1-48.

Barrett, P. (2007). Structural equation modelling: Adjudging model fit. Personality and Individual differences, 42(5), 815-824.

Bauer, M. A., Wilkie, J. E. B., Kim, J. K., \& Bodenhausen, G. B. (2012). Cuing consumerism: Situational materialism undermines personal and social well-being. Psychological Science, 23, 517-523. doi: 10.1177/0956797611429579

Belk, R.W. (1988). Possessions and the extended self, Journal of Consumer Research, 15(2), 139-168.

Brislin R. W., Lonner, W. J. \& Thorndike, R. M. (1973). Cross-cultural research methods, John Wiley and Sons, New York, USA.

Burroughs, J. E., \& Rindfleisch, A. (2002). Materialism and Well-Being: A Conflicting Values Perspective. Journal of Consumer Research, 29(3), 348-370.

Byrne, B. M. (2011). Structural equation modeling with AMOS Basic concepts, applications, and programming (Multivariate Applications Series), Routledge, New York.

Byrne, B. M. (2013). Structural equation modeling with Mplus: Basic concepts, applications, and programming. Routledge.

Calder, B.J., Lynn, W.P., \& Alice, M. (1981). Designing research for application. Journal of Consumer Research, 8, 197-207.

Campbell, Colin (1987). The Romantic Ethic and the Spirit of Modern Consumerism, New York: Basil Blackwell.

Clump, M. A., Brandel, J. M., \& Sharpe, P. J. (2002). Differences in environmental responsibility between materialistic groups. Psychologia: An International
Journal of Psychology in the Orient, 45(3), 155-161. http://dx.doi.org/10.2117/psysoc.2002.155.

Egan, V., Chan, S., \& Shorter, G. W. (2014). The Dark Triad, happiness and subjective well-being. Personality and Individual Differences, 67, 17-22.

Emmons, R. A. (1984). Factor analysis and construct validity of the narcissistic personality inventory. Journal of Personality Assessment, 48(3), 291-300.

Finch, J. F., West, S. G., \& MacKinnon, D. P. (1997). Effects of sample size and nonnormality on the estimation of mediated effects in latent variable models. Structural Equation Modeling: A Multidisciplinary Journal, 4(2), 87-107.

Fornell, C., \& Larcker, D. F. (1981). Structural equation models with unobservable variables and measurement error: Algebra and statistics.

Garver, M. S., \& Mentzer, J. T. (1999). Logistics research methods: employing structural equation modeling to test for construct validity. Journal of business logistics, 20(1), 33.

Gecas, V. (2009). The Self as a Social Force, available at: https://books.google.com.tr/books?hl=tr\&l$\mathrm{r}=$ \&id=2Nazn5H_cNYC\&oi=fnd\&pg=PA85\&dq=Gecas,+Viktor+(2009).+The+Self+as+a+Social+Force.\&ots $=$ u0SaFh2Ec4\&sig=PPP1Bdpd5V2K6MfPfXSYh6pdBuA\&redir_esc $=y \# v=$ onepage $\& q \& f=-$ false (accessed 4 April 2018).

Ger, G. \& Belk, R.W. (1996). Cross-cultural differences in materialism. Journal of Economic Psychology, 17, 55-77.

Griffin, M., Babin, B. J. \& Christensen, F. (2004). A crosscultural investigation of the materialism construct: Assessing the Richins and Dawon's materialism scale in Denmark, France, and Russia . Journal of Business Research, 57(8), 893 - 900 .

Hair, J. F., Jr., Black, W. C., Babin, B. J., Anderson, R. E. \& Tatham, R. L. (2006). Multivariate data analysis (6th Ed.), Pearson Prentice Hall, New Jersey.

Hayward, M. L., \& Hambrick, D. C. (1997). Explaining the premiums paid for large acquisitions: Evidence of CEO hubris. Administrative science quarterly, 103-127.

Heatherton, T. F. \& Vohs, K. D. (2000). Interpersonal evaluations following threats to self: Role of self-esteem. Journal of Personality and Social Psychology, 78, 725-736.

Hirschman, E. C. \& LaBarbera, P. A. (1990). Dimensions of possession importance. Psychology \& Marketing, 7(3), 215-233. 
Hofstede, G. (1990). Cultures and organizations: Software of the mind. New York: McGraw-Hill.

Hofstede, G. (2001). Culture's consequences: Comparing values, behaviors, institutions, and organizations across nations. Thousand Oaks, CA: Sage

Holman, R. H. (1981). Apparel as communication, avaliable at: http://acrwebsite.org/volumes/12220/ volumes/sv04/SV-04 (accessed 4 April 2018).

Hu, L. T., \& Bentler, P. M. (1999). Cutoff criteria for fit indexes in covariance structure analysis: Conventional criteria versus new alternatives. Structural equation modeling: a multidisciplinary journal, 6(1), $1-55$.

Johnson, R. E., Silverman, S. B., Shyamsunder, A., Swee, H. Y., Rodopman, O. B., Cho, E. \& Bauer, J. (2010). Acting superior but actually inferior? Correlates and consequences of workplace arrogance. Human Performance, 23(5), 403-427.

Karabati, S. \& Cemalcilar, Z. (2010). Values, materialism, and well-being: A Study with Turkish university students. Journal of Economic Psychology, 31(4), 624-633.

Kasser, T (2002). The High Price of Materialism. MIT Press, London.

Kastanakis, M. N. \& Balabanis, G. (2012). Between the mass and the class: Antecedents of the bandwagon luxury consumption behavior. Journal of Business Research, 65(10), 1399-1407.

Kilbourne, W. \& Pickett, G. (2008). How materialism affects environmental beliefs, concern, and environmentally responsible behavior. Journal of Business Research, 61, 885-893.

Kline, R. B. (2005). Principles and practice of structural equation modeling (2nd ed.). New York: Guilford Press.

Kurt, A., \& Paulhus, D. L. (2008). Moderators of the adaptiveness of self-enhancement: Operationalization, motivational domain, adjustment facet, and evaluator. Journal of Research in Personality, 42(4), 839-853.

Lee, J., Ko, E., \& Megehee, C. M. (2015). Social benefits of brand logos in presentation of self in cross and same gender influence contexts. Journal of Business Research, 68(6), 1341-1349.

Levy, S.J. (1959). Symbols for sale, Harvard Business Review, 37(4), 117-124.

Lewis, M. (2016). Self-conscious emotions: Embarrassment, pride, shame, guilt, and hubris in Lewis, B. \&
Jones H. (Ed.). Handbook of emotions, Guilford Press, New York, 792-814.

Lewis, M. (2000). Self-conscious emotions: Embarrassment, pride, shame, and guilt. In Lewis, M.\& Haviland-Jones, J. M. (Ed.). Handbook of emotions 2nd ed., Guilford Press, New York, 623-636.

Locke, K. D. \& Nekich, J.C. (2000). Agency and communion in naturalistic social comparison. Personality and Social Psychology Bulletin, 26(7), 864-874.

Maheswaran, D. \& Shavitt, S. (2000). Issues and New Directions in Cultural Psychology. Journal of Consumer Psychology, 9(2), 59-66.

Mardia, K. V. (1970). Measures of multivariate skewness and kurtosis with applications. Biometrika, 57(3), 519-530.

Markus, H.R., \& Kitayama, S. (1991). Culture and the self: Implications for cognition, emotion, and motivation. Psychological Review, 98, 224-253.

Newman, B. M. \& Newman, P. R. (2014). Development through Life: A psychosocial approach, available at https://books.google.com.tr/books?id=_Vk8AwAAQBAJ\&pg=PA61\&hl=tr\&source=gbs_toc_r\&$\operatorname{cad}=4 \# \mathrm{v}=$ onepage $\& \mathrm{q} \& \mathrm{f}=$ false (accessed 05 April 2018).

Nunnally, J. C. \& Bernstein, I. H. (1994). Psychometric theory (3rd Ed.). McGraw-Hill, New York, NY.

Paulhus, D. L. \& Williams, K. M. (2002). The dark triad of personality: Narcissism, machiavellianism, and psychopathy. Journal of Research in Personality, 36(6), $556-563$.

Podsakoff, P. M. \& Organ, D. W. (1986). Self-reports in organizational research: Problems and prospects. Journal of Management, 12(4), 531-544.

Richins, M. \& F.W. Rudmin, (1994). Materialism and economic psychology. Journal of Economic Psychology, 15, 217-232.

Richins, M. L. \& Dawson S. (1992). Consumer values orientation for materialism and its measurement: Scale development and validation. Journal of Consumer Research, 19(3), 303-316.

Rigdon, E. E. (1996). CFI versus RMSEA: A comparison of two fit indexes for structural equation modeling. Structural Equation Modeling: A Multidisciplinary Journal, 3(4), 369-379.

Ruvio, A., Shoham, A. \& Shlomo, H. (2007). Consumers' arrogance: Construct conceptualization and preliminary validation evidence. Available at http:// www.acrwebsite.org/volumes/v34 (accessed 4 April 2018). 
Ruvio, A. A. \& Shoham, A. (2016). Consumer arrogance: Scale development and validation. Journal of Business Research, 69(10), 3989-3997.

Shrum, L. J., Wong, N., Arif, F., Chugani, S. K., Gunz, A., Lowrey, T. M...Sundie, J. (2013). Reconceptualizing materialism as identity goal pursuits: functions, processes, and consequences. Journal of Business Research, 66(8), 1179-1185.

Silverman, S. B., Johnson, R. E., McConnell, N., \& Carr, A. (2012). Arrogance: A formula for leadership failure. The Industrial-Organizational Psychologist, 50(1), 21-28.

Singelis, T. M. (1994). The measurement of independent and interdependent self-construals, Personality and Social Psychology Bulletin, 20(5), 580-591.

Sirgy, M. Joseph (1998). Materialism and Quality of Life. Social Indicators Research, 43, 227-260.

Solomon, M. (1983). The role of products as social stimuli: a symbolic interactionism perspective. Journal of Consumer Research, 10, 319-329.

Steenkamp, J.M. \& Baumgartner, H. (1998). Assessing measurement invariance in crossnational consumer research. Journal of Consumer Research, 25, 78-90.

Tabachnick, B. G. \& Fidell, L. S. (2007). Using multivariate statistics (5th Ed.). Pearson Allyn \& Bacon, Upper Saddle River, NJ.

Tracy, J. L. \& Robins, R. W. (2007). The psychological structure of pride: A tale of two facets. Journal of Personality and Social Psychology, 92(3), 506.

Triandis, H.C., \& Marin, G. (1983). Etic plus emic versus pseudoetic: A test of basic assumption of contem- porary cross-cultural psychology, Journal of Cross Cultural Psychology, 14(4), 489-500.

Verbeke, W., Belschak, F. \& Bagozzi, R. P. (2004). The adaptive consequences of pride in personal selling. Journal of the Academy of Marketing Science, 32 (4), 386-402.

Veselka L, Giammarco, E. A., Vernon, P. A. (2014). The Dark Triad and the seven deadly sins. Personality and Individual Differences, 67, 75-80.

Vignoles, V. L., Golledge, J., Regalia, C., Manzi, C. \& Scabini, E. (2006). Beyond self-esteem: Influence of multiple motives on identity construction. Journal of Personality and Social psychology, 90(2), 308-333.

Webster, C. \& Beatty, R. C. (1997). Nationality, materialism, and possession importance. Advances in Consumer Research, 24 (1), $204-210$.

Watchravesringkan, K. (2012). Cross-cultural equivalence of materialistic values scale (MVS): An exploratory study between the United States and Thailand. Journal of Targeting, Measurement and Analysis for Marketing, 20, 235 - 253.

Wong, N., Rindfleisch, A. \& Burroughs, J. (2003). Do reverse-worded items confound measures in cross-cultural consumer research? The case of material values scale. Journal of Consumer Research, $30(1), 72-91$.

Zait, A. \& Mihalache, C. M. (2014). How do we value what we see on tv? Television's consumption and the cultivation of materialism in Romania. International Business and Economic Review, 5, 24-43. 


\section{Appendix}

A. The retained and deleted items from original 21-item CA scale (Ruvivo \& Shoham, 2016) are shown in Table 3.

Table 3: A list of retained and deleted items from CA and materialism scales

\section{CA scale}

Image-Based Consumption

IBC 1. I prefer to buy only name brands. ${ }^{a}$

IBC 2. I look mostly for name brands when I shop. ${ }^{\mathrm{a}}$

IBC 3. I tend to buy only in prestigious stores. ${ }^{a}$

IBC 4. I try to buy only expensive products. ${ }^{\text {a }}$

IBC 5. The image of a product affects my purchase of it. ${ }^{b}$

IBC 6 . I often buy products that emphasize my social status. ${ }^{b}$

Exhibitionism-based purchasing

EBP 1.I tend to buy products that attract attention. ${ }^{b}$

EBP 2. I tend to buy products that make me look meticulous. ${ }^{b}$

EBP 3. I make sure to wear clothes that lead others to compliment me. ${ }^{\text {a }}$

EBP 4. I prefer to buy products that make others think that I am fashionable. ${ }^{a}$

EBP 5 . I love it when people show interest in what I buy. ${ }^{a}$

EBP 6. It is important to me that others realize that I have the best things. ${ }^{a}$

Consumers'bragging

CB 1. I like to show others what I buy. ${ }^{a}$

$C B$ 2. I frequently make sure that others know what I buy. ${ }^{a}$

CB 3. I always tell others how my purchases are the best. ${ }^{a}$

CB 4. I like to compare the things I have with others. ${ }^{\text {a }}$

CB 5. I tend to choose showy products. ${ }^{b}$

Consumers'superiority

CS 1. Compared to others, I usually know what the best buy is. ${ }^{a}$

CS 2. Not many people know the best buy as well as I do. ${ }^{a}$

CS 3. I tend to buy better products than most people I know. ${ }^{\text {a }}$

CS 4. I usually know where to get the best deals better than others. ${ }^{a}$

${ }^{\mathrm{a}}$ Indicates retained items, ${ }^{\mathrm{b}}$ deleted items, and ${ }^{*}$ reverse items. 
B.The retained and deleted items from original 18-item Materialism scale (Rihcins \& Dawson, 1992) are shown in Table 4.

Table 4: A list of retained and deleted items from materialism scale

\section{Materialism scale}

\section{Success}

MS 1. I admire people who own expensive homes, cars, and clothes. ${ }^{\text {a }}$

MS 2. Some of the most important achievements in life include acquiring material possessions. ${ }^{\mathrm{a}}$

MS 3.I don't place much emphasis on the amount of material objects people own as a sign of success ${ }^{b^{*}}$

MS 4. The things I own say a lot about how well I'm doing in life. ${ }^{\text {b }}$

MS 5. I like to own things that impress people. ${ }^{\text {** }}$

MS 6. I don't pay much attention to the material objects other people own. ${ }^{\mathrm{a}}$

Centrality

MC 1. I usually buy only the things I need. ${ }^{\text {b* }}$

MC 2. I try to keep my life simple, as far as possessions are concerned. ${ }^{\text {* }}$

MC 3. The things I own aren't all that important to me. ${ }^{\text {b }}$

MC 4. I enjoy spending money on things that aren't practical. ${ }^{a}$

MC 5. Buying things gives me a lot of pleasure. ${ }^{b^{*}}$

MC 6. I like a lot of luxury in my life. ${ }^{\text {a }}$

MC 7. I put less emphasis on material things than most people I know. ${ }^{\text {* }}$

Happiness

$\mathrm{MH}$ 1. I have all the things I really need to enjoy life. ${ }^{\mathrm{a}^{*}}$

MH 2. My life would be better if I owned certain things I don't have. . $^{*}$

MH 3. I wouldn't be any happier if I owned nicer things. ${ }^{\text {a }}$

MH 4. I'd be happier if I could afford to buy more things. ${ }^{\text {a }}$

MH 5. It sometimes bothers me quite a bit that I can't afford to buy all the things I'd like. ${ }^{\text {b }}$

${ }^{\text {a }}$ Indicates retained items, ${ }^{\text {b }}$ deleted items, and * reverse items. 